\title{
KREATIVAN HUB U KOMPLEKSU ELEKTROLUXA- PROJEKTOVANJE ENTERIJERA
}

\section{CREATIVE HUB IN ELECTROLUX COMPLEX-INTERIOR DESIGN}

\begin{abstract}
Oblast - ARHITEKTURA
Kratak sadržaj - Revitalizacijom kompleksa u HUB, dobili smo različite prostore koje direktno komuniciraju sa javnošću $i$ publikom, kroz rad galerija, ateljea, coworkinga $i$ drugih programskih prostora. Sam cilj projekta jeste funkcionalno rešenje kompleksa, stvaranje manjih ambijenta u kompleksu $i$ na kraju sam dizajn prostora (materijali, osvetljenje). Reanimacijom prostora teži se stvaranju novog ambijenta koji će biti prijatan, kvalitetan prostor.
\end{abstract}

Nemanja Jović, Fakultet tehničkih nauka, Novi Sad drugim centrima. slične programe.
Ključne reči: Dizajn, enterijera, nameštaj, tekstura, boja

Abstract - With the revitalization of the complex in HUB, we got different spaces that directly communicate with the public and the public, through the work of galleries, studios, coworking and other program spaces. The goal of the project is a functional solution of the complex, the creation of smaller ambiences in the complex and finally the design of the space (materials, lighting). By reanimating the space by creating a new ambience that will be a pleasant, quality space.

Keywords: Design, interior, furniture, textura, colour

\section{UVOD}

Tema rada predstavlja revitalizaciju kompleksa Elektrolux u kreativan HUB. Kompleks spada u industrijsko nasleđe i nalazi se u ulici Lasla Gala 32. Novi Sad. Tema predstavlja $\mathrm{i}$ enterijersko rešenje tri pograma $\mathrm{u}$ kompleksu.

Zadatak projekta jeste osmisliti funkcionalnost prostora, da korisnici mogu ne ometano druge da koriste prostor. Dizajnom enterijera dobiti prijatnu atmosferu i ambijent, obezbediti dovoljne količine dnevnog osvetljenja uz komibinaciju veštačkog svetla.

Broj programa koji se nalazi u HUB zavisi isključivo od površine objekta. Projektni zadatak za HUB na Grbavici je uključivao programe za izdavanje prostora, izložbeni prostor, čitaonicu, kafe_bar i prostor za administaciju.

\section{OBLAST ISTRAŽIVANJA}

Centar je mesto koje pruža prostor za edukaciju, stvaranje, izlaganje i takmičenje. Dolazi do povezivanja

\section{NAPOMENA:}

Ovaj rad proistekao je iz master rada čiji mentor je bila dr Ivana Miškeljin. pojedinica unutar centra, ali isto tako dolazi do spajanja sa

Male su razlike između centara, uglavnom svi sadrže

Administracija rukovodi i vodi računa o centru i korisnicima. Za večinu prostora potrebno je da budeš član Hub-a, uglavnom su prostori za izdavanje. Prostori gde se ne dešavaju stalno neko zbivanja, uglavnom se projektuju kao multifunkcionalni, sala za predavanja, izložbeni prostor, prostor za radionice. Mogu se pojaviti i kancelarije za izdavanje raznim udruženjima, mladim firmama u razvoju. Hub-u najviše doprinose programi kao što su atelje, coworking, primaju najviše korisnika. Za korisnike je veoma bitan prostor čajna kuhinja i lounge zona, to je prostor gde mogu odmoriti i napraviti pauzu.

\section{PRISTUP TEMI}

Studija slučaja služi za analizu izvedenih projekata i enterijera. Da vidimo kako su se arhitekte suočili sa prednostima i nedostacima u prostoru, kakva su rešili funkcionalnost prostora i dizajn enterijera, koje su odabrali materijale, kako osvetljenje utiče na prostor. Na osnovu svega toga mi pronalazimo inspiraciju za svoj projekat i zato je studija slučaja veoma bitan detalj pri dizajniranju enterijera. Prikazani enterijeri za studiju slučaja su birani zbog njihovog dizajna, kombinacija materijala $\mathrm{i}$ osvetljenja $\mathrm{u}$ prostoru $\mathrm{i}$ funkcionalnosti prostora.

\section{Transforming Gallery}

Postavljanjem prozirnih pregrada koje se spuštaju sa plafona, arhitekta uspeva laku transformaciju prostora, promena visine plafona, definisane svetleće kutije, modularno svetlo, prostor za predgrađivanje. Prostor galerije je čist, zidovi su obrađeni u beloj boji, dok je pod odrađen od glaziranog betona. Sistem pokretnih prozirnih pregreda omogućava kontrolu svetlosti u prostoru i unapred programirani scenariji pregrada omogućavaju brze prostorne transformacije,čineći prostor fleksibilnim i prilagodljivim različitim namenama [1].

\section{Daily Coffeehouse}

Kafe se sastoji od dve zone. Prva zona je zona sa šankom a druga je prostor za sedenje. Da je kafe podeljen u dve zone to možemo uočiti kakav je dizajn u prostoru. Vidimo da je prva zona kafea dizajnirana u svetlijem tonu, korišćene su prirodne boje, drvo kao materijal i osvetljenje je dosta jače. 
Druga zona je intimnija zona gde su korišćene malo tamnije boje i dosta manje osvetljenja u prostoru. Vidimo odličnu kombinaciju crvene, zelene boje sa drvetom [2].

\section{Flamingo Shangai Office}

Glavni pokretač za arhitekte je bila lokacija prostora, potkrovlje. Trebalo je poboljšati postojeće stanje i osmisliti prijatnu atmosferu. Korišćenjem open space sistem za kancelarije, krov se utapa u prostor i nije za sebe celina, već sve funkcioniše kao jedan prostor. Pruža se prelep pogled na konstrukciju krova i svi korisnici imaju dostupno prirodno osvetljenje. Zbog velikog broja otvora, svaki deo prostora dobija prirodno osvetljenje, arhitekte su imale mogućnost da koriste tamnije materijale. Pojavljuje se beton kao dominantan materijal u enterijeru.

Crna čelična konstrukcija krova i crno drvo su odlična kombinacija sa betonom. Pojavom svetlog drveta na zidovima prostor dobija novi oblik, osveženje u prostoru i razbija utisak hladne nijanse enterijera [3].

\section{PROCES PROJEKTOVANJA}

Analizom izvednih projekata, uviđamo prednosti i nedostatke pri projektovanju i dizajniranju. Zaključujemo da je odabir materijala, boja i osvetljenja najbitna stavka tj. kakvu kombinaciju mogu sve dati. Takođe je veoma bitno i ko su korisnici prostora, na osnovu toga možemo obratiti više pažnje na stvari koje su potrebne.

Veliku ulogu igra osvetljenje, ako je u pitanju prirodno osvetljenje ambijent je prijatniji, korisnicima je dosta komfornije u prostoru. Ako je veštačko, onda treba tražiti adekvatnu zamenu za prirodno. Kolorit u prostoru ne treba da bude napadan, uglavnom treba koristiti mirnije hladnije tonove. Kao i obrade plafona treba u svetlije tonove.

Tamniji tonovi daju utisak manjeg prostora, zatvaraju prostor. Ubacivanjem zelenila $\mathrm{u}$ prostor, dobijamo prijatnu atmosferu. Pri odabiru zelenila treba voditi računa koje zelenilo može u prostor, koliko zahteva prirodnog osvetlenja.

\subsection{Koncept}

Koncept K. Huba je da se sastoji iz tri celine-objekta koje su međusobno povezane. Prvu celinu-objekat mogu svi stanovnici grada da koristi, i ako nisu članovi K. Huba, dok ostale dve celine uglavnom mogu da koriste samo članovi Huba.

Prva celina-objekat i jedini koji gleda na ulicu, je ogranizovan tako da u prizemlju ima galerijski prostor, salu za sastanke i kancelariju za administraciju. Galerijski prostor se nastavlja na kafe_bar (druga celina-objekat). U prizemlju trećeg objekata nalazi prostor promenljive namene, može da služi za radionice, predavanja, kao izložben prostor..

Na prvom spratu u prvom delu se nalazi kancelarije za udruženja, sala za sastanke, biblioteka i čitaonica. Biblioteka sa čitaonicom se nadovezuje na čajnu kuhinju, lounge zonu koja služi za odmor, gde se korisnici Huba mogu odmarati družiti se sa drugim korisnicima i ona se nalazi u drugom delu kompleksa. Takođe na prvom spratu se nalazi i prostor za rad, coworking koji se izdaje po potrebi korisnika.

$\mathrm{Na}$ drugom spratu Huba nalaze se celi prostori za izdavanje. Uglavnom su to prostori za male firme, koje su u razvoju ili tek počinju sa radom. Prostor je namenjen za arhitektonski biro i studio za grafički dizajn. Oba lokala imaju ulazni prostor, prostor za rad, salu za sastanke, razlika je samo u tome što arhitektonski biro sadži i prostor za pravljenje maketa, maketarnicu.

\subsection{Galerijski prostor}

Galerijski prostor nalazi se u prizemlju kompleksa. Prostor ima pogled na ulicu Lasla Gala i stvara se mogućnost privlačenja ljudi sa ulice kad je u pitanju izložba, manifestacija. Pored galerije, imamo i recepciju, portirnicu koja služi za kontrolu cirkulacije ljudi. Plan galerije je slobodan, uglavnom služi da sam umetnik određuje kakvu vrste izložbe želi. Osvetljnje je postavljeno u vidu track lights, da bude na trakama i da se pomera $u$ zavisnosti od postavke izložbe. Prostoru je dostupno i dnevnom osvetljenje preko ogromnih otvora na prednjoj fasadi. U slučaju da dnevno svetlo narušava izgled postavke, tu su i zavese o jačeg materijala, pliša da zaustave prodiranje dnevnog svetla u prostor.

U galeriji se pojavljuje i ogroman zid, koji ima ulogu konstruktivnu. Isto tako može umetnicima služiti kao deo postavke, da li u vidu murala, tapete ili kao postavka okačena na zid, slika 1. Obrada zidova je ostavljena u beloj boji, nema nikakvih detalja na zidovima, da bi fokus korisnika prostora bila na izložbu. Obrada poda je glazirani beton, i predstavlja odličnu kombinaciju sa belom bojom. Što se tiče nameštaja, postavka za izložbu je promenljiva, i u zavisnosti od izložbe ona se postavlja ili sklanja. Tu su i stolice, koje uglavnom služe za odmor ili ako neko želi da sedi i da posmatra postavku, lako su pomerljive pa ih je lako i kontrolisati u prostoru.

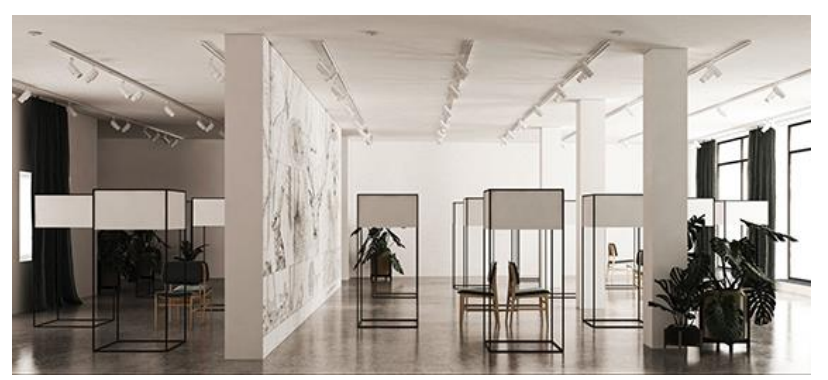

Slika 1. Prikaz na galerijski prostor

\subsection{Kafe_Bar}

Kafe_Bar nalazi se u prizemlju dvorišta kompleksa. Uglavnom služi za korisnike Huba, ali isto tako postoji mogućnost da koriste i drugi ljudi. Kafe služi i kao topla veza izmedju objekata. Nadovezuje se na galeriju, za vreme kulturnog događaja, izložbe, manifestacije kafe_bar može služiti kao mesto spremanje koktela i gdje bi ljūdi došli i uslužiti se.

Sastoji se od prostora za goste i pomoćne prostorije. Prostor za goste deli se u dve zone, prva zona je šank i druga je prostor za sedenje. Šank ima kapacitet 10 ljudi, a prostor za sedenje oko 30-40 ljudi, u zavisnosti od potrebe 
za određene događaje dolazi do mogućnosti povećanja broja kapaciteta ljudi, slika 2 .

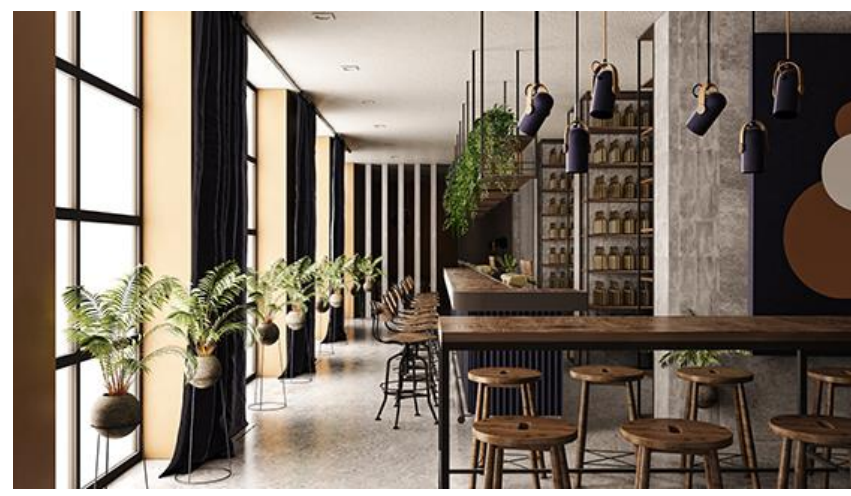

Slika 2. Prikaz na kafe_bar

Sam oblik prostora i njegova konstrukcija su definisali poziciju i dimenzije šanka. Šank ima kapacitet od 10. stolica, iznad sedenja nalazi se polica koja se spušta sa plafona. Postavljanjem police iznad sedenja postavalja se jasna granica šanka, a postavljanjem zelenila na njoj doprinosi se prijatnijoj atmosferi u prostoru. Radna površina šanka je od drveta u kombinaciji sa metalnom crnom lajsnom. Zid koji nosi radnu površinu je obložen dekorativni limom ofarbanim u plavu boju.

Ostatak prostora je funkcionalno popunjen prostorom za sedenje u kombinaciji sa zelenilom. Pod je odrađen $u$ glaziranom betonu, zidovi su odrađeni u kombinaciji beton i boje RAL 1034. Prostoru je dostupno prirodno osvetljenje, šank je dodatno osvetljenjen sa led trakom postavljenoj u polici iznad sedenja, a prostor je osvetljen i sa ugradnim svetlom i visilicama okačenim na različitim visinama. Većina nameštaja je dizajnirana po meri, autorsko delo. Dizajn barske stolice pripada Loft design studio, dizajn stolice za nisko sedenje je Tonet chair.

\subsection{Coworking prostor}

Coworking nalazi se u trećem objektu na prvom spratu. Prostor Huba se izdaje na mesec, više meseci ili godinu, sve zavisi od korisnika. Sastoji se od ulaznog hola, sala za sastanke i prostora za rad.Ulazni hol ujedno služi kao čekaonica, i nadovezuje se na dve sale za sastanke, u prostoru se nalaze i dva phone booth-a koji služe za sastanke preko interneta. Prostor za rad se deli na dve celine, rad za stolu i malo opuštenija varijanta gde postoji mogućnost rada na sofi tj. ležernijem nameštaju. U prostoru se nalaze i ormarići koji služe korisnicima za odlaganje stvari, ujedno služi kao vizuelna preprika, pojavljuju se betonski stubići koji imaju istu ulogu pregrade, takođe služe kao pomoć konstrukciji.

Kapacitet coworkinga je preko 30 korisnika. Objekat se u istoriji bavio se industrijom, pa je dizajn prostora odrađen $\mathrm{u}$ industrijskom stilu, pod $\mathrm{u}$ betonu, crni metal. Dodavanjem zelenila, prostor dobija na kvalitetu. Obrada zidova je kombinacija betona i boje RAL 5013. Coworking je osvetljen i prirodnim i veštačkim osvetljenjem, slika 3. Veštačko osvetljenje se sastoji od visilica i track lights. Visilice su postavljene iznad radnih površina, track lights se nalaze iznad hodnika i po potrebi mogu se pomerati. Većina nameštaja je dizajnirana po meri, ormarići stolovi su dizajnirani baš za coworking $u$ industrijskom stilu, autorsko delo. Dizajn radne stolice pripada studiju Lievore Altherr Molina.

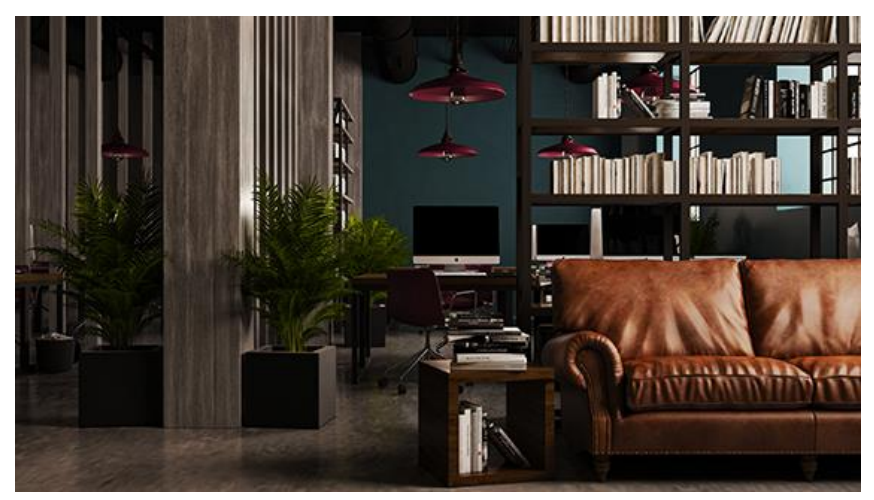

Slika 3. Prikaz coworking prostor

\section{ZAKLJUČAK}

Objekat $\mathrm{u}$ istoriji se bavio industrijom, želići da ostavim duh prošlosti makar kroz enterijer, ako nije programski, enterijer je odrađen u idnustrijskom stilu, uglavnom fine kombinacije hladniji tonova sa betonom $\mathrm{i}$ zelenim $\mathrm{u}$ prostoru.

Enterijer Kreativnog Huba je odrađen u industrijskom stilu.

\section{LITERATURA}

[1] Archdaily

(https://www.archdaily.com/939679/transforming-galleryjroc-design?

ad_source $=$ myarchdaily\&ad medium $=$ bookmark$\underline{\text { show\&ad_content=current-user) }}$

[2] Archdaily ( https://www.archdaily.com/914476/dailycoffeehouse-sivak-and-

partners/5ca7783d284dd1e433000342-daily-coffeehousesivak-and-partners-

photo?ad_source=myarchdaily\&ad_medium=bookmark$\underline{\text { show \&ad_content=current-user) }}$

\section{[3] Archdaily}

(https://www.archdaily.com/521451/flamingo-shanghaioffice-neri-and-hu-design-and-research-

office?ad_source $=$ myarchdaily \&ad medium $=$ bookmarkshow\&ad content=current-user)

\section{Kratka biografija:}

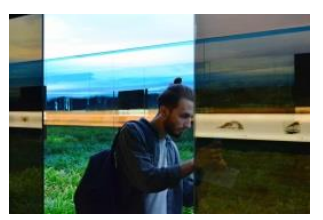

Nemanja Jović rođen je u Faidu, Švajcarska 1995. god. Osnove studije arhitekture na Fakultetu tehničkih nauka je upisao 2014. godine, a završio 2019. Iste godine upisuje master smer na Fakultetu tehničkih nauka Dizajn enterijera.

kontakt:

nemanjaarh95@gmail.com 